\title{
Influence of the Bhagavad Gita on R.W. Emerson's essay "The Transcendentalist". Uplifting the philosophy of Immanuel Kant to its highest level by R.W. Emerson.
}

\author{
${ }^{1}$ Shiva Durga , ${ }^{2}$ Prof. Dr. Anoop Gupta, ${ }^{3}$ Dr.Nitin Bhatnagar \\ ${ }^{1}$ Asst. Professor, English Department, Institute of Applied Sciences and Humanities, GLA University, \\ Mathura. U.P. India. \\ ${ }^{2}$ Director, Institute of Applied Sciences and Humanities, GLA University, Mathura. \\ ${ }^{3}$ Dr. Niting Bhatnagar, HOD English Department, GLA University, Mathura
}

\section{Introduction:}

R.W. Emerson's idealist and transcendental concepts like- Nature, the trinity of truth, goodness and beauty, lack of hypocrisy, intuition, great soul, connection of thoughts and motives with circumstance, relation of the self with the attribute less, to the Over Soul (Brahman), God within, law of Karm, Own Nature, modes of Nature, deity or personal God and its relation with everything divine, concepts of materialist and idealist are from the Bhagavad Gita. The philosophy of Immanuel Kant relating the Universe, the material and the mind was so complete that only a "Great Soul" like Emerson could uplift this philosophy to its highest philosophical level of Idealism, (of unity of soul and Brahman) hence creating an epoch, a completion and perfection to be reached by thought. Both Kant and Emerson actually formulated concepts that were present in Vedic Dharm. I have shown Emerson's idealist transcendentalist concepts are Vedic Hindu concepts.

\section{The impact of the Bhagavad Gita on R.W.Emerson:}

PG1: ${ }^{1}$ R.W. Emerson states, "The first thing we have to say respecting what are called new views here in New England, at the present time, is, that they are not new, but the very oldest of thoughts cast into the mould of these new times". This is as per the Bhagavad Gita 4.1-4.8. Sri Krishna tells Arjun that he instructed this (Bhagavad Gita) Yogic knowledge, which is imperishable, to the Sun God Vivasvan and from him through Manu, the progenitor of mankind, this knowledge was handed in disciplic succession. We see here that Yogic knowledge of the Bhagavad Gita is imperishable. Only it is revealed to the world through 'Great Souls' at different times, like the ones mentioned above. BG 4.2 states "The supreme Yogic knowledge was received in disciplic succession and understood by saintly kings. But in the course of time the succession was broken and therefore appears to be lost". BG 4.3 states "That same Yogic science is being explained by me to you". Both R.W. Emerson and the Bhagavad Gita consider 'New views' thus to be only the oldest thoughts cast into new times. Swami Vivekanand also expresses the same view. "It (the Vedantic religion's) sanction is the eternal nature of man, its ethics are based upon the eternal spiritual solidarity of man" 2 and "Our first principle is that all that is necessary for the perfection of Man and for attaining unto freedom is there in the Vedas. You cannot find anything new. You cannot go beyond a perfect unity ...."3 We see in "Compensation" Pg-58 that R.W. Emerson considers Indian mythology to correctly express "A plain confession of the in working of the All and of its moral aim". R.W. Emerson's concept of Over Soul as Brahman and his 'Moral aim' is expressed in Dharm, Karam and Bhakti Yog is brought out in this paper in 'Self Reliance', 'Circles', 'Over Soul' and elsewhere. So Vedic ideas are beyond time and operative in all time. The Bhagavad Gita is a repository of Vedic ideas which have entered American culture as 'New idea' through R.W. Emerson. R.W. Emerson could achieve this only because he is a 'Great Soul'. This concept of R.W. Emerson is explained in 'Self Reliance' and 'Circles'. It is as per BG 4.7- .8, 10.41. As per Swami Vivekanand "And it is here that the study of different religions helps us. It shows us that the same thoughts that we have been calling ours and ours alone, were present hundreds of years ago in others, and some even in a better form of expression than our own" ${ }^{4}$ This is as per the view of R.W. Emerson above. R.W. Emerson further states "The light is always identical in its composition, but it falls on a great variety of objects, and by so falling is first revealed to us, not in its own form, for it is formless, but in theirs; in like manner, thought only appears in the objects it classifies. What is popularly called Transcendentalism among us, is Idealism;" We see here that thought and the formless appears only in the form of objects it classifies; the Bhagavad Gita classification of Jati Dharm and Swadharm as seen in the sub head of 'Self Reliance' is based on 'own thought', 'own nature' and 'own work' concepts of the Bhagavad Gita and R.W. Emerson. These are brought out in the above statements of Emerson also. Hence Emerson's 'thought' here refers to and is as per Vedic thought. We have seen in 'Over Soul' that it contains the 
concept of 'Formless' and hence 'formless light' refers to Nirgun Brahman concept of the Bhagavad Gita. Hence R.W. Emerson's 'Transcendentalism' and 'idealism' contain and are based on these Vedic concepts.

R.W. Emerson states, "Every materialist will be an idealist; but an idealist can never go backward to be a materialist". So I infer Transcendentalism is the ultimate and the highest goal of every one. A person becoming a Yogi (a practitioner of Bhakti, Karm Yogas) never regresses backward into materialism from the progress he has made as per BG Chapter 12. As seen above Emerson's 'idealism' includes these Yogas of the Bhagavad Gita and hence the above observation of R.W. Emerson on the 'idealist' being unable to 'go backward to be a materialist'.

R.W. Emerson states, "The materialist, secure in the certainty of sensation ... and believes that his life is solid... Yet how easy it is to show him, that he also is a phantom walking and working amid phantoms and that he need only ask a question or two beyond his daily questions, to find his solid universe growing dim and impalpable before his sense". This is as all is governed by the Law of Karm. This has been seen in 'Compensation'. We see in 'Circles' Page 163, that as per BG 14.19, "the enlightened being does not consider anyone as the doer besides the modes of Nature". This is as per R.W. Emerson's view above. R.W. Emerson states "Even the materialist Condillac, perhaps the most logical expounder of materialism, was constrained to say, Though we should soar into the heavens, though we should sink into the abyss, we never go out of ourselves; it is always our own thought that we perceive." What more could an idealist say?" We see through correct logic on 'own thought' and 'own nature' every materialist will reach the conclusion to idealism. As seen above these are concepts of both R.W. Emerson and the Bhagavad Gita. The ability to reach correct conclusion in an argument or analysis through logic is called "Vad". This is an aspect of Brahman as per BG 10.32. We see this in R.W. Emerson's analysis above. He has finally and permanently resolved the argument of materialism and idealism. He is also able to notice correct thought, here in the case of 'Condillac' "we never go out of ourselves;" This is R.W. Emerson's concept of 'own nature' and 'own work'. This includes 'own thought'. This is as per BG 3.33. This is part of the BG concept of Swadharm and Jati Dharm explained in Chapter 2, 15.40-.60.. Only through these Karm Yog can be followed. As per R.W. Emerson these concepts of the BG are 'idealism'. We see these concepts in 'Self Reliance'.

Pg 2: R.W. Emerson states, (To the idealist) "Mind is the only reality, of which men and all other natures are better or worse reflectors". This is as per BG 6.5-6.7 which describe that one must progress to perfection with the help of one's mind. The mind can be both the friend and enemy of the conditioned soul. For one who has conquered the mind has reached already Brahman. Hence 'Mind is the only reality' and as per state of mind (Sattvic, Rajasic and Tamasic) persons are 'better or worse reflectors' of this.

R.W. Emerson states, "Although in his action overpowered by the laws of action, and so, warmly cooperating with men, even preferring them to himself, yet when he speaks scientifically, or after the order of thought, he is constrained to degrade persons into representatives of truths". R.W. Emerson states "His thought- that is the Universe". I have shown in 'Self Reliance' Page 50 that R.W. Emerson's 'principles' are as per Vedic Dharm. Hence R.W. Emerson's 'thought' is Dharmic. As per BG 14.17, 18.30-.32 Sattvic thought understands Dharm correctly. Rajasic thought is unable to understand Dharm correctly. Tamasic thought understands Dharm wrongly. Hence this is 'the order of thought', 'representatives of truths', and speaking 'scientifically' concepts of R.W. Emerson. Hence R.W. Emerson's 'idealist' thinks like the above views of the Bhagavad Gita. We see this further. 'Truth' seen from elsewhere, particularly in 'Self Reliance', 'Over Soul', 'Fate' and also later in this Essay mean practice of Dharm, constitution of thought (Sattvic, Rajasic and Tamasic), Dharmic method of living, Brahman realization. We see in 'Circles'as per R.W. Emerson, one has to discard initially vice and then also virtue to reach God (Brahman) and this is as per BG Chapter 14. One has to develop and use Satva to overcome the other modes of nature (Rajas and Tamas) (these modes of Nature or gunas are R.W. Emerson's 'order of thought') and then as per BG 14.19, 14.20 discard Satva also and attain Brahman realization. The level of progress on this is the 'representation of truth' in a person. The above concepts of the Bhagavad Gita show that the wise enlightened person categorizes 'persons into representatives of truths'. Hence R.W. Emerson's transcendental concept speaking 'scientifically, or after the order of thought' is as per BG 14.19. As per BG 14.19 "When one properly sees that in all activities no other performer is at work than these modes of Nature and knows that which is beyond the Gunas attains my spiritual Nature (Brahman)." BG 14.20 states "Having transcended the three gunas which are the cause of this body, the embodied self becomes freed from birth, death, old age, misery and enjoys immortality". 'Immortality' here is Brahman realization, different from freedom from death. This is the concept of Vidya Maya or correct knowledge.

R.W. Emerson states in 'Over Soul' Page 139 "...to indicate the heaven of this deity and to report what hints I have collected of the transcendent simplicity and energy of the Highest Law". This is as per BG Chapter 12. Sagun Brahman is deity, transcendental, simple and 'energy of the Highest Law'. Sagun Brahman is the personal aspect of the personal and impersonal God of the Vedas. Knowledge of Brahman is thus the highest Transcendental knowledge (or Law) and truth (Brahman realization) as per R.W. Emerson. This 
includes also the concept of Bhakti as seen in BG Chapter 12. This is also as per the view of Swami Vivekanand. We see in 'Over Soul' that R.W. Emerson's concept of 'Over Soul' is Brahman. 'Law' here is Dharm and the Yogas of the Bhagavad Gita.

R.W. Emerson states, "necessitating him to regard all things as having a subjective or relative existence, relative to that aforesaid Unknown Centre of him." This is the concept of 'God within' as seen in "Self Reliance". It also shows that the soul is also an aspect of Brahman or 'Over Soul' as seen in 'Over Soul'. As per BG 9.7, "All manifestations ultimately merge into Brahman and subsequently are again manifested at the beginning of another cycle of creation". Hence "all things as having a subjective or relative existence". This is also because everyone has to reach this God within (concept of Samadhi) through existence by following Dharm as per BG $2.3, .30,13.23, .25, .28, .29,18.61$. These shlokas explain the concept of 'God within'.

R.W. Emerson states, "Everything real is self-existent. Everything divine shares the self-existence of Deity." This shows the connection between Nature, Soul and Brahman. This is as per BG 9.7, 10.39, 13.13, $.16, .17,14.27,15.18$. The Soul is an aspect of Brahman. It is beyond action and time. The Jiva (Conditioned Soul) has to realize this by following Dharm. Everything in Nature except the Soul is unreal and not self existent. The Soul alone is real and self existent. This is the Vedic concept of Maya seen in 'Illusions'. Hence 'Everything real is self-existent'. We see here R.W. Emerson appreciating the personal aspect of God as 'Deity' or God with form or the Personal God of the Vedas. This aspect of God is absent and criticized in Abrahamic religions. We have seen in earlier subheads R.W. Emerson appreciated and believed in the Vedic concept of God with Form, specifically Lord Vishnu and Lord Krishna. We see in 'Self Reliance' Page 33 R.W. Emerson uses the words 'personality to the deity' with 'devout motions of the soul'. Thus we see R.W. Emerson refers to personal God or Sagun Brahman and the associated concept of Bhakti or devotion. R.W. Emerson accepts and believes that Bhakti cannot be denied or ignored when it manifests in the soul as it connects the person (conditioned soul) with 'deity'. Since the deity is Sagun Brahman, it is self existent. Brahman is present in everyone through the Bhagavad Gita concept of 'God within' which is also R.W. Emerson's concept of 'God within' that I have examined in 'Self Reliance', 'Over Soul' and also above. Men can through Bhakti as stated in Chapter 12 of the Bhagavad Gita develop love of personal God and a personal relationship with him and thus imbibe his Divinity. This has been explained in 'Circles'. Hence "Everything divine shares the self-existence of Deity".

R.W. Emerson states, "You think me the child of my circumstances: I make my circumstance. Let any thought or motive of mine be different from that they are, the difference will transform my condition and economy. I - this thought which is called I, - is the mould into which the world is poured like melted wax. The mould is invisible, but the world betrays the shape of the mould. You call it the power of circumstance, but it is the power of me. Am I in harmony with myself? my position will seem to you just and commanding. Am I vicious and insane? my fortunes will seem to you obscure and descending. As I am, so shall I associate, and, so shall I act; Caesar's history will paint out Caesar." In chapter two of the Bhagavad Gita we see that Arjun has the option whether to fight the war or not. This is accepted and stated by Krishna. Hence a person has a choice and the ability to make his circumstance. Everyone can follow Dharm and the Yogas of the Bhagavad Gita and attain Brahman realization as per BG 9.32. Thus 'I make my circumstance'. The Bhagavad Gita chapter 14 explains that a person in harmony with himself is Sattvic and practices virtue and is just. Being vicious and insane on the other hand are Tamasic qualities leading to delusion and down fall. 'Thought' hence also includes constitution of thought or the way one thinks. We see in the Bhagavad Gita that Arjun is having the association of Krishna which affects his action. The concept of "I" is present in the Bhagavad Gita as the "conditioned soul'. It is the concept of identity. Thought and motive are seen as a part of Karm Yog in 'Compensation'. As per BG 13.22 a person meets with the consequences of his 'thought or motive' thus 'makes his circumstance'. 'thought or motive' is of different grades of the modes of nature. This is Sattvic, Rajasic and Tamasic as per the Bhagavad Gita Chapter 14. A person's practice of these accordingly shapes the identity and position of a person (conditioned soul). This is 'the power of me'. Thus 'the world is poured like melted wax' into 'this thought which is called I'. 'I' is the conditioned soul of the Bhagavad Gita hence this is the 'mould'. The above comparison and the sameness with the Bhagavad Gita shows that R.W. Emerson's 'thought or motive' is as per the Vedic concept.

R.W. Emerson states, "but if you ask me, Whence am I? I feel like other men my relation to that Fact which cannot be spoken, or defined, nor even thought, but which exists, and will exist". This explains the relation between the 'soul' and the 'Brahman' as brought out in 'Over Soul'and 'Self Reliance'. R.W. Emerson here states the characteristics of Brahman as brought out there. The characteristics of Brahman are being beyond 'speech' or 'definition' or 'thought' and 'which exists and will exist'. This is as per BG 9.7, 10.39, 12.1-.4, 13.19, 14.26-.27, 15.18. This shows the 'I' of R.W. Emerson is the conditioned soul (Jiva) which realizes the unity of soul with Brahman as per the above shlokas of the Bhagavad Gita.

R.W. Emerson states, "that Transcendentalism is the Saturnalia or excess of Faith; the presentiment of a faith proper to man in his integrity". 'Excess of faith' is the "God intoxicated state" of R.W. Emerson which 
is the same as the concept of Bhakti. This is covered in 'Circles'. 'Faith' is as per BG 4.33, 9.3, 10.14, 17.13, $17.28,4.40,6.24,18.71$. We see here 'integrity' is a transcendental concept. 'Integrity' has been covered as a part of the Bhagavad Gita in 'Self Reliance'. 'Integrity' there is expressed as a method of living. This is following Dharm and the Yogas. We also see here 'Excess of faith' through 'integrity' also refers to 'own qualities' in the individual which is a part of the individual's 'own work' and 'own nature'. These concepts of R.W.Emerson are a part of Swadharm explained in BG Chapter 2, 18.40, .41, .45-.50.Swadharm includes 'own nature', 'own work', 'own thought'. We see here R.W.Emerson expresses them to be transcendental concepts. Hence Swadharm and Dharm is transcendental.

PG 3: R.W. Emerson states 'Nature is transcendental'. We have seen R.W. Emerson's concept of 'Nature' as contained in the Bhagavad Gita in the sub head of 'Nature' and is as per BG Chapter 13. "Yet genius and virtue predict in man the same absence of private ends, and of condescension to circumstances," We see 'genius and virtue' as concepts of the Bhagavad Gita in 'Self Reliance' and 'Compensation' respectively. We see that 'virtue' is vicarious and 'genius' is for the well being of society and mankind since they are an aspect of Dharm. Hence they preclude 'private ends'. We see in BG 18.51-.53 that Dharm requires 'the absence of private ends'. This is also because as per BG 5.25 benefit of all life is an aim of Dharm, Swadharm, 'own nature'. I have shown in 'Self Reliance' that R.W. Emerson's concept of 'genius' consists of Swadharm and 'own nature'. Hence too the 'absence of private ends'. The indifference to circumstance is a part of Karm Yog and has been brought out in 'Self Reliance'. We see here that these concepts of the Bhagavad Gita too are transcendental concepts.

\section{Derivation of the Transcendental concept of Immanuel Kant:}

I will now show that Immanuel Kant's concepts lead directly to Vedic concepts. Immanuel Kant differs from empiricists and rationalists on aspects of the concept of 'a priori' thus evolving a new concept, albeit a blend of these theories. Kant states that 'a priori' Knowledge is 'transcendental', or based on the form of all possible experience, while a posteriori knowledge is empirical, based on the content of experience. Kant states that a priori, or, transcendental conditions are seated in one's cognitive faculties and are not provided by experience in general or experience in particular (thus being independent of content of experience). Concepts of Time and cause are counted among the list of pure 'a priori' forms. So time and cause are operative in every one's cognitive faculties. Otherwise they would not simultaneously experience the world as an orderly and well governed place. This claim is popularly known as Kant's transcendental deduction and is the foundational and central argument of his monumental work, the critique of pure reason. I discern it follows that everyone is subject to Time and cause. This is as per BG 10.30, .33, 11.32 (Concept of time) and BG 13.22(cause).

As seen earlier, R.W.Emerson was the towering leader and inspiration for the Transcendentalist Movement. The word 'Transcendental' was taken from Immanuel Kant. The concept of transcendental deduction doesn't avoid the objectivity of time and cause, but attempts to make a case for the fact of subjectivity and the relationship between subjectivity, objectivity and empirical (content). I discern Time and cause inexorably lead to action, or Karm. I have explained Karm as a subject of the Bhagavad Gita in 'Self Reliance' . Killing a man though objective and empirical has different subjective and also objective contexts, whether it was an act of burglary, for gaining property, an act in self defence or in the line of duty or in War. These have different connotation; (we see R.W.Emerson justified War). The subjective here will also include one's motives and feelings. This is according to the Law of Karm in BG 13.22. Accordingly the Law of Karm carries different effects to the doer. Law of Karm has been explained in 'Compensation'.

As such the law of Karm interacting with the individual takes into account subjectivity, objectivity and the empirical and their inter relation through Time and Cause. In fact Swami Vivekanand sees Vedic influence and Vedic concepts in the concepts of Kant. Swami Vivekanand states "This is one of the highest points to understand of Advaita Vedanta, this idea of Maya...Those of you who are acquainted with Western philosophy will find something very similar in Kant...It was Shankara who first found the identity of time, space and causation with Maya, ...so even that idea was here in India." "The Indian prince Dara shuko translated the Upanishads into Persian, and a Latin translation of the same was seen by Schopenhauer whose philosophy was moulded by these. Next to him, the philosophy of Kant also shows traces of the teachings of the Upanishads." R.W.Emerson states, "It is well known to most of my audience, that the Idealism of the present day acquired the name of Transcendental, from the use of that term by Immanuel Kant, of Konigsberg, who replied to the skeptical philosophy of Locke, which insisted that there was nothing in the intellect which was not previously in the experience of the senses, by showing that there was a very important class of ideas, or imperative forms, which did not come by experience, but through which experience was acquired; that these were intuitions of the mind itself;" Hence intuition of the mind does not come by experience but experience itself is acquired through 'intuitions of the mind'. This is as per BG 14.19 "When one properly sees in all activities no other performer is at work than these modes of nature". Hence 'experience' itself is an aspect of modes of Nature (Sattvic, Rajasic and Tamsic) and its according thought and Constitution of thought. BG 14.19 further states "and he knows the 
Supreme Lord who is Transcendental to all these modes". Thus we are led to Brahman by "intuitions of the mind' and thus attain 'Brahman nature'. Thus time, space and causation are transcended. This is because Brahman is beyond and transcendental to these, this is shown in BG 9.7, 10.39, 12.2-.4, 13.31- .32, 14.26-.27, 15.16-21. This is also as per the observation of Swami Vivekanand "Kant's great achievement was the discovery that 'time, space and causation are modes of thought' but Vedanta taught this ages ago and called it 'Maya ${ }^{7}$ We see R.W.Emerson agrees with my analysis and this opinion of Swami Vivekanand. R.W.Emerson states on Page 2 of this essay, "His thought, — that is the Universe". This is the concept of 'Own Nature' and 'Own Thought' discussed above as the part of the Bhagavad Gita. This is a part of Swadharm and Dharm. This leads to Brahman. This is as per BG 9.7,10.39,13.32,15.16-.21. These shlokas seen along with BG 14.19-.20 show that 'Intuition' has 'all authority over our experience'. This is as per the observation of R.W.Emerson here. From this essay and 'Self Reliance' we gather as per R.W.Emerson 'intuitions' or 'transcendentalism' actually leads to Brahman and is the path to it; Dharm and the Yogas and thus is Sanatan Dharm. R.W.Emerson states "and he denominated them Transcendental forms. The extraordinary profoundness and precision of that man's thinking have given vogue to his nomenclature, in Europe and America, to that extent, that whatever belongs to the class of intuitive thought is popularly called at the present day Transcendental".

R.W.Emerson states, Although, as we have said, there is no pure Transcendentalist, yet the tendency to respect the intuitions, and to give them, at least in our creed, all authority over our experience, has deeply colored the conversation and poetry of the present day; and the history of genius and of religion in these times, though impure, and as yet not incarnated in any powerful individual, will be the history of this tendency." From this we understand there is a very important class of ideas, which are responsible for acquiring experience; called 'intuitive thought', or 'Transcendental'. R.W.Emerson further understands 'genius' as Transcendental. R.W.Emerson also understands 'Nature' as Transcendental. We see in 'Self Reliance' that 'genius' is actually a part of 'Swadharm' and through it also a path to Brahman. We see in 'Self Reliance' that R.W.Emerson had 'intuition' and 'inspiration of 'aboriginal self', explained as teaching of Brahman and this is 'primary wisdom'. He was among the few persons, or 'great soul', in the world to have it. We see here that 'intuition' and 'inspiration' is also Transcendental. Swami Vivekanand also expresses this view "Inspiration (is) transcendental knowledge" 8 " ...it came from within themselves (great teachers). The Yogi teaches that the mind itself has a higher state of existence, beyond reason, a super conscious state, and when the mind gets to that higher state, then this knowledge, beyond reasoning, comes to man. Metaphysical and Transcendental knowledge comes to that man." 9 We see through this and also elsewhere in the paper that R.W. Emerson's concept of 'religion' is Sanatan Vedic Hindu Dharm. We also see here the concept of 'God within' as responsible for "intuitions of the mind" and thus transcendental knowledge comes to 'great teachers'. This is as per BG 4.7, 4.8, 10.41, from them it is transmitted to the world for the welfare of the mankind and all living beings, this is a concept of Dharm as per the above shlokas and BG4.1-.8, 5.25.

R.W.Emerson here clearly expects his above ideals to be 'incarnated in' a 'powerful individual'. From my analysis and views above and also my explanation of the Bhagavad Gita it is clear that such a 'great soul' or 'powerful individual' is Swami Vivekanand and R.W. Emerson is his eternal Divine associate. Hence R.W.Emerson had insight on 'incarnation' of Swami Vivekanand. The Vedic concept of incarnation holds that like the flower, roots, stem and leaves of a lotus plant are connected, a divine incarnation manifests with his eternal divine associates. This is like the incarnation of Lord Ram, Goddess Sita, Sri Laxman and Sri Hanuman. R.W. Emerson is Swami Vivekanand's divine associate also because Swami Vivekanand planted Vedanta or Sanatan Hindu Dharm in Western culture. Western Culture was made conducive and receptive for this from within by the fertilizer of R.W. Emerson's philosophy. We note no such implantation could take place in African or Islamic cultures by Swami Vivekanand. The following observations are required for perspective. Swami Vivekanand was a disciple of Sri Ramakrishna. Swami Vivekanand states "(As per the statement of Sri Adi Sankar in Vivek Chudamani) through great tapasya (penance) I have secured refuge with a great soul (his Guru). ${ }^{10}$ Sri Rama Krishna correctly followed and appreciated the great incarnate Vedic saints particularly Sri Adi Sankaracharya, Sri Ramanuj and Sri Chaitanya. Sri Rama Krishna stated "Sankaracharya was a Brahmjnani" "11 "Sankaracharya kept the 'ego of knowledge' (to teach men) otherwise men's heart will not be illuminated". "A man can teach only if God reveals himself to him and gives the command. Narad, Suka... and Sankara had it too". ${ }^{13}$ He stated "Chaitanyadeva's knowledge had the brilliance of the Sun of knowledge. Further he radiated the soothing light of the moon of devotion. He was endowed with both the knowledge of Brahman and ecstatic love of God" 14 "The Great souls deeply affected by the sufferings of men, show them the way to God. Sanakaracharya kept the ego of knowledge in order to teach mankind. The gift of knowledge and devotion is far superior to the gift of food. Therefore Chaitanyadeva distributed Bhakti to all, including the out caste". ${ }^{15}$ Satchidanda (Brahman) emanating out of the body of Sri Rama Krishna revealed to Sir Rama Krishna that he was its incarnation. ${ }^{16}$

The task which Sri Rama Krishna undertook through Vivekanand was to implant Sanatan Vedic Dharm into the West and also reinvigorate it in India. The statements of Sri Rama Krishna are relevant. "The time will 
come when he (Vivekanand) will shake the world to its foundations through the strength of his spiritual powers". "The Hindu religion alone is Sanatan Dharm. The various creeds you hear of nowadays have come into existence through the will of God and will disappear again through his will... The Hindu religion has always existed and will always exist" ${ }^{18}$. Through the progress of Western civilization and growing world interest in Indian Vedic Dharm the above prophesies of Sri Ramakrishna are attaining fullness and realization.

PG4:

R.W.Emerson states, "The popular literary creed seems to be, 'I am a sublime genius; I ought not therefore to labor.' But genius is the power to labor better and more availably. Deserve thy genius: exalt it" In the Mahabharat Arjun was required to follow his duty not for his private benefit but for duty's sake. This is Swadharm and Karm Yog explained in BG Chapter 2,3,5. I have explained this in 'Self Reliance' and 'Compensation'. This includes welfare of mankind and all life as per BG 5.25. Arjun was proficient in his work, hence he was addressed as 'Mahabayo' by Krishna in the Bhagavad Gita Chapter 2. Thus 'to labor better and more availably' is seen as a concept of Swadharm and Dharm. Thus 'genius' is a part of Swadharm. This is as per the observation of R.W.Emerson above.

Pg 5: R.W.Emerson states, "Unless the action is necessary, unless it is adequate, I do not wish to perform it". This is part of Swadharm and Karm Yog. Duty has to be done for duty's sake as per Karm Yog. Necessary and adequate action is to be performed. This is as per BG Chapter 2, 3, 5. "I do not wish to do one thing but once. I do not love routine. Once possessed of the principle, it is equally easy to make four or forty thousand applications of it. A great man will be content to have indicated in any the slightest manner his perception of the reigning Idea of his time, and will leave to those who like it the multiplication of examples". R.W. Emerson's 'great man' indicates the 'principle' or 'the reigning Idea of his time' which others have to follow through various applications. This is shown in the BG 3.20-21. King Janak attained perfection through following Karm Yog and its concept of prescribed duties. Thus he demonstrated the principle which others have to follow, through 'application' in their own lives through the concept of Swadharm. This is as per the view of Swami Vivekanand "What is meant by a Rishi? The pure one. Be pure first, and you will have power... When you are a Rishi you will find that others obey you instinctively. Something mysterious emanates from you, which makes them follow, makes them hear you, makes them unconsciously, even against their will, carry out your plans. That is Rishihood." ${ }^{19}$. I conclude therefore from R.W. Emerson's thoughts that R.W. Emerson is a Vedic Rishi. R.W.Emerson here demonstrates the application of his 'great man' concept on himself. Today we find the intelligent and wise shaping Western culture through following R.W.Emerson.

R.W.Emerson states, "If I cannot work, at least I need not lie. All that is clearly due to-day is not to lie". This shows one has to discard Hypocrisy and lies and be truthful. This is seen in 'Self Reliance' as a concept of the Bhagavad Gita. Requirement of speaking the truth and being truthful to oneself is as per BG 10.4, 10.32, 17.15. In BG Chapter 2 Krishna asks Arjun to discard hypocrisy and also deluded perception which was preventing him from doing his 'own work'.

Pg 6: R.W.Emerson states "In the eternal trinity of Truth, Goodness, and Beauty". We see 'truth' in "Self Reliance", 'goodness' in "Compensation" and "beauty' in "Beauty" as concepts of the Bhagavad Gita.

R.W.Emerson states, "Let them obey the Genius then most when his impulse is wildest; then most when he seems to lead to uninhabitable deserts of thought and life; for the path which the hero travels alone is the highway of health and benefit to mankind. What is the privilege and nobility of our nature, but its persistency, through its power to attach itself to what is permanent?" We see here 'genius' is "for the benefit to mankind". This is as per the Bhagavad Gita 5.25 which states that Dharm and Karm Yog are for the welfare and wellbeing of society. This leads to Brahman which is permanent. We see here R.W. Emerson's concept of 'Great Soul' as "the Hero" who 'travels alone'. 'Genius' here is a part of "Own Nature". Hence it is a part of Swdharm. It should be depended upon in every circumstance especially in time of difficulty. This is shown in BG Chapter 2. This is as per Krishna's advice to Arjun in chapter 2, 3 and specially BG 3.33 regarding 'Own Nature' as seen in of 'Self Reliance'. Thus one 'travels alone'.

The word 'Transcendental' was used by Rubin Carter (then convict and later freed by the Court). A legal technicality was preventing his attorneys from appealing to a Higher Court (as then they would have lost 'new evidence' forever) and so compelling them to approach a lower court which was not favourable as it had earlier delivered a biased judgement resulting in conviction. In such situation Rubin asked his attorneys to 'transcend' the law and approach the higher court. The ensuing judgement held that the prosecution had been "predicated upon an appeal to racism rather than reason and concealment rather than disclosure." And set aside the conviction freeing Rubin. ${ }^{20}$ This helped in eradicating racism (another of Emerson's ideals) from the working of legal prosecution culture in America. The word 'Transcendental' is used multifariously in English translations of the Bhagavad Gita by various saints, scholars and authors thus following the footsteps of Swami Vivekanand, because they following the footsteps of Swami Vivekanand, find R.W. Emerson's concepts to be as per the concepts of the Bhagavad Gita. 
R.W.Emerson states, "Amidst the downward tendency and proneness of things, when every voice is raised for a new road or another statute, or a subscription of stock, for an improvement in dress, or in dentistry, for a new house or a larger business, for a political party, or the division of an estate, - will you not tolerate one or two solitary voices in the land, speaking for thoughts and principles not marketable or perishable? Soon these improvements and mechanical inventions will be superseded; these modes of living lost out of memory; these cities rotted, ruined by war, by new inventions, by new seats of trade, or the geologic changes: - all gone, like the shells which sprinkle the sea beach with a white colony to-day, forever renewed to be forever destroyed. But the thoughts which these few hermits strove to proclaim by silence, as well as by speech, not only by what they did, but by what they forbore to do, shall abide in beauty and strength, to reorganize themselves in nature, to invest themselves anew in other, perhaps higher endowed and happier mixed clay than ours, in fuller union with the surrounding system".

Material creation is subject to permanent circle of creation and destruction. This is as per the Vedic concept of cycle of Yugas which leads to destruction and renewal. Voices for improvement in Material creation may achieve improvement, but ultimately this too is destroyed in 'forever renewed and forever destroyed' cycles. This is as per BG 9.7, 10.39. Hence such voices are a part of "The downward tendency and proneness of things'. This is as per BG Chapter 13 and 14 which explain the aims for material to be below aims for spiritual. Principles of marketability belong to 'Arth' and are lower than the stage of Brahman realization. But different from these voices of all are one or two 'solitary voices'. They speak of thoughts and principles not 'marketable or perishable'. The thoughts of the 'few hermits' 'shall abide'. We see these 'hermits' thoughts from the essay to be 'genius' ( seen as a part of Swadharm in "Self Reliance" and also here) 'Nature, the trinity of truth, goodness and beauty, lack of hypocrisy, intuition, great soul, connection of thoughts and motives with circumstance, unity of soul with Brahman, Brahman realization, God within, law of Karm, Bhakti and Karm Yogas, Own Nature, modes of Nature, 'deity' or personal God and its relation with 'everything divine', concepts of 'materialist' and 'idealist'. These have been explained by me as concepts of the Bhagavad Gita in 'Self Reliance', 'Experience', 'Circles', 'Conduct of Life'and Compensation'and here. Hence the Bhagavad Gita contains R.W.Emerson's 'idealist' and 'transcendental' concepts. The fact of these concepts reorganizing themselves anew in cultures or 'clay' has been seen on Pg 1 . We have seen above that both Immanuel Kant and R.W.Emerson actually formulated concepts that were present in Vedic Dharm. Moreover they were influenced and inspired by Vedic Dharm.

Before Immanuel Kant the human mind was grappling and struggling with the concept of 'a priori' and of thought itself till it reached its completion in the philosophy of Immanuel Kant. Many philosophers after Kant tried to add his philosophy. But the philosophy of Immanuel Kant relating the Universe, the material and the mind was so complete that they all failed. It was only a 'Great Soul' like Emerson who could uplift this philosophy to its highest philosophical level of Idealism, of Brahman realization and unity of soul and Brahman, hence creating an epoch, a completion and perfection to be reached by thought, this cannot be added to since as stated by Swami Vivekanand, "You cannot go beyond a perfect unity". ${ }^{21}$ I have shown R.W. Emerson's 'idealist', 'transcendentalist' concepts are Vedic Hindu concepts.

\section{Reference:}

[1]. http://www.emersoncentral.com/transcendentalist.htm. Hereafter Emerson's quotations from this reference are in italics with relevant Pg. No.

[2]. The Complete Works of Swami Vivekananda. Advaita Ashrama Publication May1999 Edition, ISBN 81-85301-46-8, Vol.3, Pg.251.

[3]. The Complete Works of Swami Vivekananda. Advaita Ashrama Publication May1999 Edition, ISBN 81-85301-46-8, Vol.3, Pg.249-250.

[4]. Religion of Love, Swami Vivekananda, Advaita Ashrama Publication, March 1999, ISBN 81-7505-091-8, Pg. 90.

[5]. The Complete Works of Swami Vivekananda. Advaita Ashrama Publication May1999 Edition, ISBN 81-85301-46-8, Vol.3, Pg.341-342.

[6]. The Complete Works of Swami Vivekananda. Advaita Ashrama Publication May1999 Edition, ISBN 81-85301-46-8, Vol.3, Pg.435.

[7]. The Complete Works of Swami Vivekananda. Advaita Ashrama Publication May1999 Edition, ISBN 81-85301-46-8, Vol.7, Pg.50.

[8]. The Complete Works of Swami Vivekananda. Advaita Ashrama Publication May1999 Edition, ISBN 81-85301-46-8, Vol.1, Pg.183.

[9]. The Complete Works of Swami Vivekananda. Advaita Ashrama Publication May1999 Edition, ISBN 81-85301-46-8, Vol.1, Pg.183.

[10]. The Gospel of Sri Ramakrishna. Published. Sri Ramakrishna Math. ISBN-7120-435-X, Pg. 936.

[11]. The Gospel of Sri Ramakrishna. Published. Sri Ramakrishna Math. ISBN-7120-435-X, Pg. 248

[12]. The Gospel of Sri Ramakrishna. Published. Sri Ramakrishna Math. ISBN-7120-435-X, Pg. 940.

[13]. The Gospel of Sri Ramakrishna. Published. Sri Ramakrishna Math. ISBN-7120-435-X, Pg. 141

[14]. The Gospel of Sri Ramakrishna. Published. Sri Ramakrishna Math. ISBN-7120-435-X, Pg. 485

[15]. The Gospel of Sri Ramakrishna. Published. Sri Ramakrishna Math. ISBN-7120-435-X, Pg. 379

[16]. The Gospel of Sri Ramakrishna. Published. Sri Ramakrishna Math. ISBN-7120-435-X, Pg. 720.

[17]. Vedanta Kesari, ISSN 0042-2983, Vol.100, No5. May 2013, Pg 20

[18]. The Gospel of Sri Ramakrishna. Published. Sri Ramakrishna Math. ISBN-7120-435-X, Pg. 642.

[19]. The Complete Works of Swami Vivekananda. Advaita Ashrama Publication May1999 Edition, ISBN 81-85301-46-8, Vol.3 Pg. 296.

[20]. Carter VS Rafferty, $621 \mathrm{~F}$ supp 533, 534 (DNJ 1985).

[21]. The Complete Works of Swami Vivekananda. Advaita Ashrama Publication May1999 Edition, ISBN 81-85301-46-8, Vol.3 Pg.250 